Case 3 is a rare congenital abnormality of the inner ear which usually presents as recurrent meningitis. This abnormality is now well documented. ${ }^{4}$ It should be suspected as a cause of recurrent meningitis in a child who has a sensorineural deafness. The presence of fluid behind the tympanic membrane should make one suspicious and the diagnosis can be confirmed by tomograms of the inner ear. The CSF fistula is from the fundus of the internal auditory canal into the vestibule of the inner ear and from there into the middle ear through a defect in the stapes footplate. The simplest and safest way to close this defect is through the middle ear.

A fluid level behind the tympanic membrane is usually due to secretory otitis media. In patients with meningitis or CSF rhinorrhoea, the possibility that the fluid in the middle ear may be CSF should be considered.
We thank our neurosurgical colleagues for referring these cases.

\section{References}

1 Anonymous. Deaths from bacterial meningitis. $\mathrm{Br} \mathrm{Med} \mathrm{J}$ 1973 ; i: 623.

2 Baird D R, Whittle H C, Greenwood B M. Mortality from pneumococcal meningitis. Lancet 1976; ii: 1344-6.

${ }^{3}$ Spink W W, Su C K. Persistent menace of pneumococcal meningitis. JAMA 1960; 173: 1545-8.

4 Parisier S C, Birken E A. Recurrent meningitis secondary to idiopathic oval window CSF leak. Laryngoscope 1976; 86: $1503-15$.

Correspondence to K P Manning FRCS, Walton Hospital, Rice Lane, Liverpool L9 1AE.

Received 8 September 1982

\title{
The Rottenrow endotracheal tube holder
}

\author{
ALISON M KERR \\ Royal Hospital for Sick Children, Glasgow
}

SUMMARY A new device is described which holds the endotracheal tube securely in the mouth of the neonate during ventilation.

Several devices have been produced, but displacement of the endotracheal tube remains one of the most common problems in neonatal nurseries. Despite its obvious disadvantages many units still prefer the security obtained by driving a large safety pin through the tiny endotracheal tube as it crosses the infant's mouth.

A device should possess the following features: (1) The grip should remain secure without occlusion of the endotracheal tube in the warm, mucusy mouth of the infant. (2) It should be able to be fixed simply from the side of the tube and allow adjustment without having to be detached from the ventilating machine. (3) It should be suitable for all sizes and types of tube used in the newborn. (4) Small loose parts which could be swallowed or inhaled should be absent. (5) It should invade the mouth as little as possible and allow oral toilet. (6) The material should be pliable so as not to damage the skin. (7) There should be a choice of fixation-tapes or adhesive. (8) It should be cheap and capable of reuse.
With these in mind a device has been designed in flexible polyvinylchloride (PVC). It has been tested and modified in use, until a shape has been arrived at which suits the nature of the material, the manufacturing process, and the clinical requirements.

\section{Nature and use of the 'Rottenrow device'}

The device is made of PVC. The endotracheal tube strap is perforated at $2 \mathrm{~mm}$ intervals by $2 \mathrm{~mm}$ holes. The stainless steel peg is two-thirds embedded in the PVC pillar (Fig. 1).

\section{Instructions}

The endotracheal tube is introduced into the infant's airway in the conventional manner. While it is supported in position by the hand in the angle of the mouth, the device, with the endotracheal tube strap open, is brought up from the side and placed so that the tube lies snugly in its groove and the narrow part of the face strap is closely applied to the upper lip. The endotracheal tube strap is then stretched round the tube and fixed with moderate tension to the steel peg. The tube must then be checked to make sure it is held firmly without occlusion. The face strap may be secured directly to 


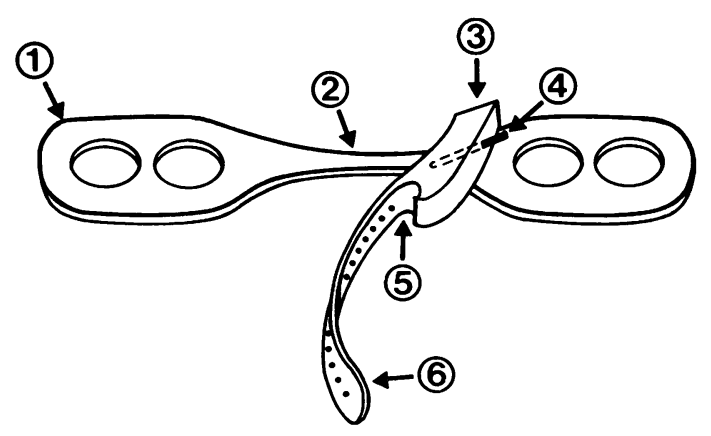

Fig. 1 The Rottenrow endotracheal tube holder (1) Face strap $1 \mathrm{~mm}$ thick. (2) This band lies on the upper lip. (3) Pillar $1 \mathrm{~cm}$ deep. (4) Stainless steel pin two-thirds embedded. (5) Groove for endotracheal tube. (6) Strap for endotracheal tube.

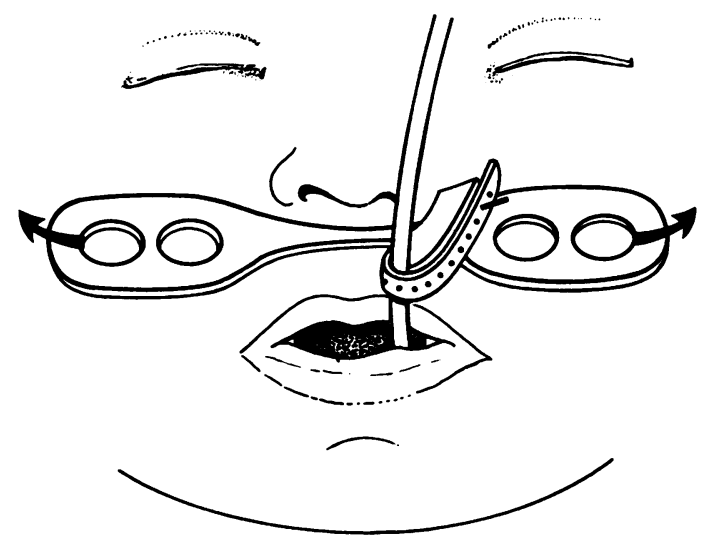

Fig. 2 Closure of endotracheal tube strap and the position of the device on the face. Arrows indicate attachment of tapes to a bonnet. the cheeks with strip adhesive, laid on a piece of two-way adhesive, or fixed to a cap on the infant's head by means of cotton tapes (Fig. 2).

\section{Comment}

The elasticity of the endotracheal tube strap allows a firm grip to be achieved on the tube while the presence of the groove prevents its occlusion. The PVC clings well to the tube even if it is warm and slippery.

By adjusting the tube strap any of the neonatal sizes of the endotracheal tube can be accommodated (including shouldered tubes). Firm tubes give the best hold, and caution must be exercised if softer tubes are used, since the safety margin between satisfactory grip and endotracheal tube occlusion is reduced. For small infants any redundant strap can be trimmed with knife or scissors.

The device can be sterilised with Cidex, Hibitane in methylated spirit, or Baby Bird solution.

Patent has been applied for.

I thank Mr Quinn, QD Plastics (Glasgow) Limited; Dr J C. Maclaurin and staff at the neonatal intensive care unit at Glasgow Royal Maternity Hospital, Rottenrow, and special care baby unit at Stirling Royal Infirmary. I am pleased that the staff of the Glasgow Royal Maternity Hospital suggested the name for the device.

The work was financially supported by the Yorkhill Research Fund and carried out mainly in the Glasgow Royal Maternity Hospital.

Correspondence to Dr Alison M Kerr, Department of Neonatal Paediatrics, 6th Floor, Royal Hospital for Sick Children, Yorkhill, Glasgow G3 8SJ.

Received 27 August 1982 